\title{
The interactions between selenium and iodine deficiencies in man and animals
}

\author{
John R. Arthur ${ }^{1 *}$, Geoffrey J. Beckett ${ }^{2}$ and Julie H. Mitchell ${ }^{1}$ \\ ${ }^{1}$ Division of Micronutrient and Lipid Metabolism, Rowett Research Institute, Greenburn Road, \\ Bucksburn, Aberdeen AB21 9SB, UK \\ ${ }^{2}$ University Department of Clinical Biochemistry, The Royal Infirmary, \\ Edinburgh EH3 9YW, UK
}

\begin{abstract}
Up to one billion people live in areas where they may be at risk from I deficiency. Many of the debilitating effects of the deficiency may be irreversible, consequently it is essential to understand the mechanisms whereby lack of I can cause disease through decreased thyroxine and 3,3',5-triiodothyronine $\left(\mathrm{T}_{3}\right)$ synthesis. Since $\mathrm{Se}$ has an essential role in thyroid hormone metabolism, it has the potential to play a major part in the outcome of I deficiency. These effects of Se derive from two aspects of its biological function. First, three Se-containing deiodinases regulate the synthesis and degradation of the biologically active thyroid hormone, $\mathrm{T}_{3}$. Second, selenoperoxidases and possibly thioredoxin reductase (EC 1.6.4.5) protect the thyroid gland from $\mathrm{H}_{2} \mathrm{O}_{2}$ produced during the synthesis of thyroid hormones. The mechanisms whereby Se deficiency exacerbates the hypothyroidism due to I deficiency have been elucidated in animals. In contrast to these adverse effects, concurrent Se deficiency may also cause changes in deiodinase activities which can protect the brain from low $\mathrm{T}_{3}$ concentrations in I deficiency. Animals with Se and I deficiency have changes in serum thyroid hormone concentrations that are similar to those observed in patients with I deficiency disease. However such animal models show no thyroid involution, a feature which is characteristic of myxoedematous cretinism in man. These observations imply that if Se deficiency is involved in the outcome of I deficiency in human populations it is likely that other interacting factors such as goitrogens are also implicated. Nevertheless the protection of the thyroid gland from $\mathrm{H}_{2} \mathrm{O}_{2}$ and the regulation of tissue $\mathrm{T}_{3}$ levels are the functions of Se that are most likely to underlie the interactions of Se and I.
\end{abstract}

Iodine: Selenium: Nutrient deficiency: Deiodinase: Cretinism

\footnotetext{
Abbreviations: BAT, brown adipose tissue; $c \mathrm{GSHPx}, e \mathrm{GSHPx}, p h \mathrm{GSHPx}$, cytosolic, extracellular and phospholipid hydroperoxide glutathione peroxidase respectively; ID-I, ID-II, ID-III, iodothyronine deiodinase types I, II and III respetively; $\mathrm{T}_{3}$, triiodothyronine; $\mathrm{T}_{4}$, thyroxine; TR, thioredoxin reductase; $\mathrm{TSH}$, thyrotropin.

*Corresponding author: Dr John Arthur, fax + 44 (0)1224 716622, email jra@rri.sari.ac.uk
} 


\section{Introduction}

\section{Consequences of iodine and selenium deficiency in man}

I deficiency in man is a major health problem. Over one billion people live in areas which have I-deficient soil, approximately 200 million people have goitre, whilst about 20 million have brain damage. I is essential for thyroid hormone synthesis, indeed this is its only known role. The clinical manifestations of I deficiency are thus considered to arise from impaired thyroid hormone production. The dietary allowance for I is approximately $150-200 \mu \mathrm{g} / \mathrm{d}$. Deficiency of the trace element gives rise to a number of clinical manifestations, which vary with age. The fetus is most affected by I deficiency with abortion, still birth and endemic cretinism being commonly found in areas of severe I deficiency. Goitre, hypothyroidism and impaired mental and physical development are found in the infant, child and adolescent. In the adult, goitre, mental retardation, decreased fertility and hypothyroidism may occur. Goitre may also arise from ingestion of goitrogens such as cassava, an important food grown in tropical areas. Consumption of cassava can give rise to increased levels of thiocyanate in the thyroid that impairs gland function. In areas where cassava is eaten the balance of the intake of I and thiocyanate appears to be critical in determining if goitre will develop (Delange \& Ermans, 1996). Thus, the manifestations of I deficiency range from mild hypothyroidism to the severest forms of cretinism. These latter diseases involve irreversible neurological damage and impaired development, highlighting the importance of recognizing and preventing endemic I deficiency.

Se deficiency in human populations is not as widespread and probably less well recognized than I deficiency. However, in China inadequate intake of Se has been associated with Keshan disease, a cardiomyopathy which occurs mainly in growing children and pregnant females $(\mathrm{Ge}$ \& Yang, 1993). A similar low Se status in Zaire in Africa does not cause cardiomyopathy, implying that additional factors are also involved in the pathogenesis of Keshan disease (Vanderpas et al. 1990). In particular, viral infection may be 'a trigger factor' which precipitates cardiomyopathy in Se-deficient Chinese subjects (Beck et al. 1995; Levander \& Beck, 1996, 1997). What is clear is that Se supplementation has almost entirely eliminated Keshan disease (Ge \& Yang, 1993). Nevertheless, there are concerns that marginal Se deficiency still causes cardiac problems in the Chinese population (Wu et al. 1997; Gu et al. 1998).

Interest in interactions between Se and I deficiency first arose from the discovery that $\mathrm{Se}$ is essential for normal thyroid hormone metabolism. This connection was first recognized as an elevated plasma thyroxine ( $\left.\mathrm{T}_{4}\right)$ concentration and a decreased plasma 3,3',5 triiodothyronine $\left(\mathrm{T}_{3}\right)$ concentration in Se-deficient animals (Arthur et al. 1987; Beckett et al. 1987). These changes were shown not to be secondary consequences of the decreased food intake that sometimes occurs with prolonged Se deficiency. The acute and specific effects of Se deficiency on thyroid hormone metabolism were therefore hypothesized to be inhibition of hepatic iodothyronine deiodinase (EC 3.8.1.4) (ID-I) which converts $\mathrm{T}_{4}$ to $\mathrm{T}_{3}$ by $5^{\prime}$ monodeiodination. Subsequently, ID-I was shown to be a Se-containing protein (Arthur et al. 1990a; Behne et al. 1990). Cloning of ID-I showed that it contained a selenocysteine at the active site coded for by a stop codon (TGA) (Berry et al. 1991a,b). Conversion of the active site selenocysteine to cysteine greatly decreased the activity of the cloned enzyme demonstrating how effective a catalyst the ionized selenocysteine group is at physiological $\mathrm{pH}$ (Berry et al. 1991c). Se deficiency in animals causes rapid and specific decreases in hepatic and renal ID-I activities (Beckett et al. 1987; Arthur et al. 1990a), emphasizing the essentiality of Se for maintaining thyroid hormone metabolism. The effects of Se deficiency on thyroid hormone metabolism are complex and are discussed in more detail later in this review. 
As well as ID-I, there are type II and type III deiodinases (ID-II, ID-III) also essential for interconversion of the biologically active and inactive forms of thyroid hormone (Arthur \& Beckett, 1994; Beckett \& Arthur, 1994; Kohrle, 1994; St Germain \& Galton, 1997; Richard et al. 1998). ID-II which occurs in brain and central nervous system tissue of animals and also in brown adipose tissue of some species converts $T_{4}$ to $T_{3}$ within these tissues. This enzyme provides an important regulatory function in such tissues since circulating $\mathrm{T}_{3}$ does not readily gain access to the intracellular nuclear receptors and thus exert biological activity (Safran et al. 1991). The development and function of the central nervous system is particularly sensitive to thyroid hormone supply and hence to the expression of deiodinase enzymes. Some tissues express ID-III, which converts $\mathrm{T}_{4}$ to the metabolically inactive reverse $\mathrm{T}_{3}$, thus bypassing the production of biologically active $\mathrm{T}_{3}$. ID-III also converts $\mathrm{T}_{3}$ to diiodothyronine, again helping to regulate precise tissue levels of $\mathrm{T}_{3}$ (Karmarkar et al. 1993; KoopdonkKool et al. 1996). During development clear changes occur in the ontogeny of the deiodinases suggesting that these enzymes may have important roles regulating thyroid hormone supply and thus the timing of switching on and off thyroid-responsive genes (Richard et al. 1998). Initial studies on the effect of Se deficiency on ID-II and ID-III provided equivocal results that could be interpreted as the enzymes being Se-containing or Se-independent (Chanoine et al. 1992; Meinhold et al. 1993). However cloning of ID-II and ID-III showed that they both contained 'in frame' TGA codons which specify selenocysteine at the active site of the enzyme (Croteau et al. 1995, 1996; Salvatore et al. 1995; Larsen, 1996). The maintenance of ID-II and ID-III activities, even in severe Se deficiency is indicative of the importance of these enzymes for normal thyroid hormone metabolism (Beckett et al. 1989; Meinhold et al. 1993; Mitchell et al. 1997).

Since the only known biological role for I in mammals is as a component of the thyroid hormones, the major basis of Se and I interactions is the synthesis and subsequent utilization of these thyroid hormones. Se however, has many biological functions and the thyroid hormone deiodinases are just three of at least thirty mammalian selenoproteins. These proteins have been identified either by purification and cloning or by in vivo labelling with ${ }^{75} \mathrm{Se}$ (Behne et al. 1988 , 1996; Evenson \& Sunde, 1988; Wu et al. 1995). The additional Se-containing proteins include four glutathione peroxidases, which provide intracellular and extracellular protection against the potentially injurious effects of $\mathrm{H}_{2} \mathrm{O}_{2}$ and lipid hydroperoxides (Sunde, 1990; Arthur et al. 1996). Additionally, the Se-containing flavoenzyme, thioredoxin reductase (EC 1.6.4.5; TR), is essential for redox regulation of certain proteins and it may also contribute to cell antioxidant systems (Gladyshev et al. 1996; Howie et al. 1998). Further extracellular antioxidant capacity may be provided by selenoprotein P. This protein contains ten selenocysteine residues, twentythree histidine residues and seventeen cysteine residues, thus indicating a large capacity to bind transition metals, which would normally initiate free radical activity (Hill et al. 1991; Burk \& Hill, 1992; Burk et al. 1995). The relevance of the latter selenoproteins to I metabolism becomes evident on consideration of the involvement of $\mathrm{H}_{2} \mathrm{O}_{2}$ in the process of thyroid hormone synthesis. Other selenoproteins such as selenoprotein $\mathrm{W}$ are not discussed in the present paper but have been reviewed elsewhere (Sunde, 1990; Arthur et al. 1996).

\section{Thyroid hormone synthesis}

Fig. 1 shows the pathway for thyroid hormone production. The functional unit for thyroid hormone synthesis is the follicle, a structure made up of clusters of thyrocytes. The lumen of the follicle is filled with colloid, which is mainly composed of thyroglobulin. This is a high molecular mass protein synthesized by thyrocytes, which is then exported and stored in the follicular lumen. Synthesis of thyroid hormones requires iodination of tyrosyl residues on 


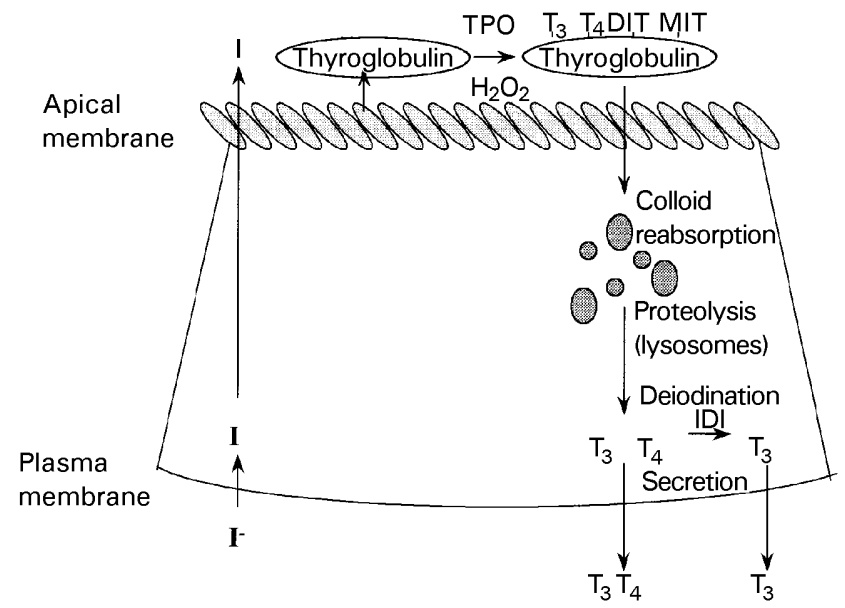

Fig. 1. The mechanism of synthesis of thyroid hormones. lodine is transported through the thyroid cell to the follicular lumen, where in the presence of hydrogen peroxide and thyroid peroxidase (TPO) it is incorporated into tyrosyl residues on thyroglobulin. The colloid is then reabsorbed into the thyrocyte from where thyroid hormones are released into the circulation after proteolytic release from thyroglobulin. DIT, diiodotyrosine; IDI, iodothyronine deiodinase; MIT, monoiodotyrosine; $\mathrm{T}_{3}$, triiodothyronine; $\mathrm{T}_{4}$, thyroxine.

thyroglobulin followed by coupling of these iodinated derivatives. These reactions take place within the follicular lumen at the surface of the apical membrane. The steps required for thyroid hormone synthesis can be summarized as follows and are reviewed in detail by Taurog (1996).

\section{Active transport of iodide}

I is usually presented to the thyroid as the inorganic form iodide. Iodide is transported into the thyrocyte and thus 'trapped' by a $\mathrm{Na}^{+}$/iodide symporter with the ion gradient being generated by a $\mathrm{Na}^{+}, \mathrm{K}^{+}$-ATPase (EC 3.6.1.37) (Dai et al. 1996). Thyrotrophin (TSH) stimulates iodide uptake probably acting through adenylate cyclase $(E C$ 4.6.1.1). Following uptake, iodide is transported across the thyrocyte into the follicular lumen.

\section{Iodination of tyrosyl residues on thyroglobulin}

This reaction takes place in the follicular lumen and leads to the formation of mono-iodo and di-iodo tyrosine residues on thyroglobulin. The reaction requires the generation of $\mathrm{H}_{2} \mathrm{O}_{2}$ in high concentrations and also the action of thyroid peroxidase (EC 1.11.1.8), an enzyme located on the luminal side of the apical membrane. The generation of $\mathrm{H}_{2} \mathrm{O}_{2}$ appears to be the rate-limiting step in thyroid hormone synthesis and is regulated by a complex network of interacting second messenger systems. In many species, including man, the production of $\mathrm{H}_{2} \mathrm{O}_{2}$ is regulated through the $\mathrm{Ca}$-phosphoinositol signalling cascade but in some animals the cAMP pathway may also be involved (Dumont, 1971; Bjorkman \& Ekholm, 1992; Corvilain et al. 1994). It has been suggested that activation of protein kinase $\mathrm{C}$, elevated free $\mathrm{Ca}^{2+}$ concentrations and the phospholipase $\mathrm{C} / \mathrm{Ca}^{2+}$ cascades may act in concert to promote $\mathrm{H}_{2} \mathrm{O}_{2}$ production. In vitro, the 
addition of the $\mathrm{Ca}$ ionophore A23187 to thyrocytes or thyroid slices can stimulate $\mathrm{H}_{2} \mathrm{O}_{2}$ formation. TSH can also promote in vitro production of $\mathrm{H}_{2} \mathrm{O}_{2}$ but only at high non-physiological concentrations. There is disagreement as to the site and mechanism of $\mathrm{H}_{2} \mathrm{O}_{2}$ generation. It has been suggested that $\mathrm{H}_{2} \mathrm{O}_{2}$ is generated in the cytoplasm of the thyrocyte through the action of superoxide dismutase $\left(E C\right.$ 1.15.1.1). $\mathrm{H}_{2} \mathrm{O}_{2}$ can then cross the apical membrane to the follicular lumen where it becomes available for reaction with thyroid peroxidase. An alternative pathway has been proposed whereby $\mathrm{H}_{2} \mathrm{O}_{2}$ is formed directly on the luminal side of the apical membrane by a flavoprotein-NADPH oxidase (EC 1.6.5.3) system. Whilst $\mathrm{H}_{2} \mathrm{O}_{2}$ is essential for thyroid hormone synthesis it is extremely toxic. Irrespective of the site of generation, the thyrocyte will be exposed to high concentrations of $\mathrm{H}_{2} \mathrm{O}_{2}$ and toxic lipid hydroperoxides. The selenoenzymes present in the thyrocytes are involved in preventing peroxidative damage and may thus represent a major function for Se in thyroid hormone metabolism.

\section{Coupling of iodinated tyrosyl residues to produce thyroid hormones}

The mechanisms by which iodinated tyrosyl residues are coupled to produce $T_{3}$ and $T_{4}$ are unclear but may involve thyroid peroxidase and $\mathrm{H}_{2} \mathrm{O}_{2}$. If two di-iodotyrosyl residues on thyroglobulin are coupled $\mathrm{T}_{4}$ is formed, whilst coupling of a mono-iodotyrosyl with a diiodotyrosyl molecule will lead to the formation of $\mathrm{T}_{3}$ or the biologically inactive isomer reverse $\mathrm{T}_{3}$.

\section{Proteolysis and thyroid hormone release}

The colloid is absorbed by pinocytosis into the thyrocyte where it undergoes proteolysis in the lysosomes to liberate thyroid hormones. This process appears to be under the influence of TSH. Further metabolism of thyroid hormones can occur by deiodination and the expression of thyroidal ID-I and ID-II selenoenzymes is regulated through the TSH receptor.

\section{Thyroid hormone production: adaptation to iodine deficiency}

In chronic I deficiency in animals and man, marked adaptations to the pathways involved in thyroid hormone synthesis take place. The changes act to maintain euthyroid status (Delange \& Ermans, 1996) and are triggered by elevated TSH levels and give rise to: increased trapping of iodide; marked increases in each of the steps involved in thyroid hormone production; increase in mono-iodotyrosyl : di-iodotyrosyl ratio on thyroglobulin thus favouring the production of $\mathrm{T}_{3}$; preferential secretion of $\mathrm{T}_{3}$; increased thyroidal mono-deiodination of $\mathrm{T}_{4}$ to produce $\mathrm{T}_{3}$; altered peripheral conversion of $\mathrm{T}_{4}$ to $\mathrm{T}_{3}$; development of goitre.

As a result, the characteristic pattern of hormones in plasma in I deficiency is increased TSH and low $\mathrm{T}_{4}$. Plasma $\mathrm{T}_{3}$ may be normal or low depending on the severity of I deficiency. The changes which occur in plasma TSH, $\mathrm{T}_{4}$ and $\mathrm{T}_{3}$ in I deficiency in human subjects appear to be agerelated, with the highest TSH and lowest $\mathrm{T}_{4}$ values appearing in young infants. It is thought that goitre may be a side effect of I deficiency rather than a beneficial adaptive response.

\section{Selenium and iodine deficiency in the thyroid}

The thyroid gland produces significant quantities of $\mathrm{H}_{2} \mathrm{O}_{2}$ for thyroid hormone synthesis. However, this peroxide can also be damaging if produced in excess and allowed to react with 
the components of the cell. Any impairment of thyroidal peroxide metabolizing systems by Se deficiency therefore will allow damage to occur in the thyrocyte. The importance of the peroxide-metabolizing enzymes is further increased in I deficiency. As I supplies decrease, levels of $\mathrm{T}_{4}$ also decrease which in turn leads to an increase in TSH production in the pituitary. This then hyperstimulates the thyroid gland and thus $\mathrm{H}_{2} \mathrm{O}_{2}$ and lipid hydroperoxide production. When Se is available extracellular glutathione peroxidase ( $E C$ 1.11.1.9) (eGSHPx), phospholipid hydroperoxide glutathione peroxidase ( $p h \mathrm{GSHPx}$ ), cytosolic glutathione peroxidase (cGSHPx), and TR may all protect against potential oxidative damage (see Howie et al. 1998). Provided supplies of Se are adequate, I deficiency results in increased production of enzymes, particularly $c$ GSHPx, with resultant enhancement of antioxidant activity (Mitchell et al. 1996). The induction of $c$ GSHPx in preference to $p h$ GSHPx suggests that it is more likely that $\mathrm{H}_{2} \mathrm{O}_{2}$ rather than lipid hydroperoxide has the potential to damage the thyroid during overstimulation; $c$ GSHPx can metabolize $\mathrm{H}_{2} \mathrm{O}_{2}$ much more effectively than $p h \mathrm{GSHPx}$. Additionally, Se and I deficiencies can change peripheral thyroid hormone metabolism and function through modulation of deiodinase activities in different organs. These latter effects have been elucidated in many animal-model studies, the results of which form the basis of much of our understanding of the combined deficiency in human subjects.

\section{Selenium and iodine deficiency in animals}

\section{Iodine deficiency}

As discussed earlier, in I deficiency the synthesis of $T_{4}$ is inhibited yet, initially, plasma $T_{3}$ concentrations are maintained due to the action of TSH on the thyroid gland increasing $\mathrm{T}_{3}$ synthesis and intrathyroidal deiodination of $\mathrm{T}_{4}$ to give $\mathrm{T}_{3}$. These responses are dependent on $\mathrm{Se}$ supply for the synthesis of ID-I, as well as glutathione peroxidase enzymes, which help to protect the thyroid tissue from the toxic effects of $\mathrm{H}_{2} \mathrm{O}_{2}$ and its highly reactive metabolites. In addition, deiodinase expression in the liver, kidney and central nervous system is modified in I deficiency. These changes are discussed here in the context of combined Se deficiency.

\section{Selenium deficiency}

Studies using Se-deficient rats indicated that the brain and endocrine organs are able to retain the element at the expense of other organs such as the liver and muscle (Behne et al. 1988). In addition, within a particular organ, there is a hierarchy of Se supply to specific selenoproteins (Bermano et al. 1995; Larsen \& Berry, 1995). In Se deficiency, this hierarchy helps to maintain plasma $\mathrm{T}_{3}$ concentrations by decreasing the hepatic catabolism as well as increasing the thyroidal synthesis of $T_{3}$ by ID-I. Despite an increase in plasma $T_{4}$ concentration in Se deficiency, plasma TSH concentration is unchanged due to an impairment of the normal negative feedback mechanism in the pituitary. However, thyroidal stores of $\mathrm{T}_{4}, \mathrm{~T}_{3}$ and $\mathrm{I}$ are decreased in Se deficiency (Arthur et al. 1990c).

\section{Combined selenium and iodine deficiency: 'long term' and 'acute' studies}

In several feeding trials, over more than one generation, plasma $\mathrm{T}_{4}$ concentrations were not significantly different between rats with combined Se and I deficiency and those with I deficiency alone (Beckett et al. 1993; Meinhold et al. 1993; Hotz et al. 1997; Wu et al. 1997; 
Mitchell et al. 1998). In addition, Meinhold et al. (1993) studied the effects of Se deficiency over three generations and I deficiency for 2 months on ID-I, ID-II and ID-III activities in the rat and found no interaction between the deficiencies. Data on the acute effects of Se and I deficiency on thyroid hormone metabolism were obtained from male weanling rats fed on diets deficient in Se, I or Se and I for 7 weeks (Beckett et al. 1993). Amounts of $\mathrm{T}_{4}, \mathrm{~T}_{3}$ and $\mathrm{I}$ in thyroid were far more depleted in combined Se and I deficiency than in Se or I deficiency alone. Furthermore, the Se- and I-deficient rats had larger thyroid glands, higher plasma TSH concentrations and higher cerebral ID-II activities than I-deficient rats. Thus, Se deficiency, at least acutely, can exacerbate some of the effects of I deficiency by increasing the hypothyroid stress on the thyroid gland.

\section{Selenium and iodine deficiency: thyroid selenoenzymes and hormones}

The hypothyroid stress of combined Se and I deficiency also occurs in female rats and their offspring at different postnatal ages (Mitchell et al. 1996, 1998). In 19-d-old pups from Ideficient and (Se- and I)-deficient rats plasma TSH concentrations were increased 25-fold and 50-fold respectively (Mitchell et al. 1996). Despite this, there were no differences between these treatment groups in the weight of the thyroid gland or in plasma $\mathrm{T}_{4}$ and $\mathrm{T}_{3}$ concentrations in adult or young rats. However, rat pups with combined Se and I deficiency had significantly lower thyroidal ID-I, $c$ GSHPx and phGSHPx activities and mRNA levels than pups that were only I-deficient. Compared with control groups thyroidal ID-I activity was increased and $c$ GSHPx activity was unchanged in Se- and I-deficient pups at $19 \mathrm{~d}$ old. In contrast thyroidal ID-I activity was unchanged and $c$ GSHPx activity was decreased by more than $50 \%$ in Se- and I-deficient pups $11 \mathrm{~d}$ old (Mitchell et al. 1998). The compensatory mechanisms that operate to retain selenoprotein function are therefore less efficient in the thyroids of the 11-d-old rat suggesting that a greater proportion of circulating $\mathrm{T}_{3}$ may be produced from de novo synthesis in neonatal, as compared with mature, rats. In addition, ID-II has recently been identified in human thyrocytes (Salvatore et al. 1996), but there is as yet no evidence for this enzyme in animal thyroid glands. As ID-II may be upregulated in I deficiency, the potential for its occurrence in animal thyroid glands and its involvement in responses to I deficiency need to be examined.

\section{Selenium and iodine deficiency and the brain}

The effects of Se and I deficiencies on brain development are variable and depend not only on the relative severity of the deficiencies but also on the stage of development at which they are induced. Despite the compensatory mechanisms to spare circulating $\mathrm{T}_{3}$ concentrations in Se and I deficiencies, the developing fetus requires a supply of maternal $\mathrm{T}_{4}$ for early brain development (Deescobar et al. 1993). More than $80 \%$ of $\mathrm{T}_{3}$ residing on the nuclear receptors in the brain appears to be derived from intracellular deiodination of $\mathrm{T}_{4}$ by ID-II. Nuclear $\mathrm{T}_{3}$ receptors have been detected in fetal rat brain by $13 \mathrm{~d}$ gestation (Perez-Castillo et al. 1985; Larsen \& Berry, 1995). The activities and expression of ID-I, $c$ GSHPx and phGSHPx in the cerebral cortex, cerebellum, mid-brain and brain stem of female rats and their offspring at $19 \mathrm{~d}$ were unaffected by Se and I deficiency. In contrast, ID-II activities were increased to the same or a greater extent than in I deficiency alone (Mitchell et al. 1997). Thus, despite the fact that the concurrent Se deficiency decreased plasma $e$ GSHPx activity to less than $15 \%$ of control levels, sufficient Se was still available to the preweanling offspring to increase brain ID-II activity more than 6-fold. ID-II activity was also increased 6-fold in the cerebral cortex of third 
generation Se-deficient rats, which were I-deficient for the final 2 months of the experiment (Meinhold et al. 1993). A similar induction of rat brain ID-II activity in experimentally-induced hypothyroidism allowed tissue $\mathrm{T}_{3}$ concentrations to remain unchanged (Serrano-Lozano et al. 1993). Consistent with this, the activities of brain cell-specific marker enzymes and expression of myelin basic protein were unchanged in Se- and I-deficient 19-d-old rats (Mitchell et al. 1997), confirming the efficiency of compensatory mechanism to maintain thyroid hormone metabolism. However, Campos-Barros et al. (1997) demonstrated a $50 \%$ decrease in tissue $\mathrm{T}_{3}$ concentrations in all brain regions, except the cerebellum, in rats which were Se-deficient for three generations and I-deficient for 2 months, despite 3-fold increases in ID-II activities. Such a change in $T_{3}$ concentrations would predispose to impaired brain development.

Selenoprotein activities in the central nervous system of 1-, 4- and 11-d-old rat pups from Se- and I-deficient mothers are less efficiently retained than in 19-d-old pups (Mitchell et al. 1998). Cerebrum $c$ GSHPx activities are decreased by $50 \%$ in 1-, 4- and 11-d-old rats with Se deficiency and concurrent Se and I deficiency. ID-II activity could not be detected in cerebrum $1 \mathrm{~d}$ after birth, but was increased 1.5-fold and 3-fold in Se- and I-deficient rats at 4 and $11 \mathrm{~d}$ old when compared with controls. This may be associated with tissue $\mathrm{T}_{4}$ supply, as in I deficiency the element is retained by the mother during pregnancy and supplied to the pup via milk, resulting in a 25 -fold increase in pup thyroidal $\mathrm{T}_{4}$ during the first week after birth (Obregon et al. 1991). Se deficiency caused a decrease in the cerebral expression of brain-derived neurotrophic factor in 4- and 11-d-old animals. The decreases were exacerbated by I deficiency in 4-d-old animals and ameliorated by I deficiency in 11-d-old animals (Mitchell et al. 1998). Although localized changes in thyroid hormone concentrations could have influenced brainderived neurotropic factor expression, other selenoproteins such as TR, which can indirectly modulate gene expression, could underlie the altered gene expression caused by Se deficiency (Gladyshev et al. 1996; McLeod et al. 1997). Myelination in the rat brain occurs at about $10 \mathrm{~d}$ after birth and is delayed in hypothyroidism as assessed by the expression of myelin basic protein (Kristensson et al. 1986). Myelin basic protein expression in I-deficient rats was the same as controls at $11 \mathrm{~d}$ old but was decreased by $50 \%$ in combined Se and I deficiency (Mitchell et al. 1998). Thus, concurrent Se deficiency may cause a further delay in brain development; however, it is unlikely that this is directly due to the similar differences in tissue $\mathrm{T}_{4}$ concentrations which occur in I deficiency and combined Se and I deficiency (CamposBarros et al. 1997).

\section{Selenium and iodine deficiency: the potential for thyroidal damage}

The lack of, or in some cases a very small, difference in plasma $\mathrm{T}_{3}$ concentrations between Ideficient, and Se- and I-deficient rats suggests that the thyroid gland is able to retain sufficient Se to produce $\mathrm{T}_{3}$ either by de novo synthesis or by deiodination of $\mathrm{T}_{4}$ by ID-I. This may be at the expense of increased peroxidative damage to the gland; however, thyroid atrophy characteristic of myxoedematous cretinism is not observed in rats (Beckett et al. 1993; Meinhold et al. 1993; Mitchell et al. 1996, 1998). The role for Se deficiency in thyroidal damage has also been investigated in rats by feeding Se-deficient and normal rats with goitrogens to destroy their thyroid gland and then re-feeding them with iodide (Contempre et al. 1993). Although the duration of deficiency and the stage of development at which it was induced were not exactly comparable with Se and I deficiency in human subjects, the results showed that thyroid cells from Se-deficient rats were more necrotic on iodide re-feeding than were those from Se-adequate, goitrogen-fed rats. In addition, the thyroid gland morphology was 
restored to normal within $15 \mathrm{~d}$ of iodide administration in Se-sufficient, but not in Se-deficient, rats (Contempre et al. 1995). The thyroid degeneration in Se- and I-deficiency was thought to be due to impaired defence against oxidative damage since methimazole, which inhibits I oxidation by the thyroid peroxidase system, protected against the iodide-induced necrosis. Furthermore, selenium deficiency increased the necrosis induced by free radicals in other organs including liver and kidney (Burk et al. 1995). The fibrosis and permanent damage to thyroid tissue characteristic of myxoedematous cretinism could also reflect Se-induced disturbance in the inflammatory response which follows necrosis (Contempre et al. 1996). An influx of macrophages which in turn secreted an excess of the cytokine, transforming growth factor type $\beta$ led to changes in the proliferation indexes of epithelial cells and fibroblasts and ultimately led to fibrosis. Anti-transforming growth factor $\beta$ antibodies decreased the macrophage invasion and prevented necrosis within $15 \mathrm{~d}$ of iodide administration (Contempre et al. 1996). The authors hypothesized that the mechanism underlying this overproduction of transforming growth factor $\beta$ by the macrophages may also play a role in the aetiology of other Se-related disorders such as Kashin-Beck disease. However, Se deficiency alone is not sufficient to initiate this disease (Morenoreyes et al. 1998).

\section{Selenium and iodine deficiency and brown adipose tissue}

Rodent and human brown adipose tissue (BAT) contains ID-II activity and the $\mathrm{T}_{3}$ generated by this enzyme is thought to play an important role in thermogenesis via regulation of the tissuespecific uncoupling protein (Bianco et al. 1988). In Se-deficient rats, BAT ID-II activity was decreased by $60 \%$ and the normal increase in ID-II activity induced by cold stress was attenuated; BAT ID-II activity after $18 \mathrm{~h}$ at $4{ }^{\circ}$ was 10 -fold lower in Se-deficient than in Se-sufficient animals (Arthur et al. 1991). Thus, Se deficiency may impair the thermogenic response to cold and pose a substantial threat to neonates. BAT ID-II activity is increased in I deficiency, but the increase is reversed by a concurrent Se deficiency and the levels of uncoupling protein are decreased (Geloen et al. 1990; Mitchell et al. 1997). A decrease in BAT $\mathrm{T}_{3}$ concentrations is likely as a consequence of low plasma $\mathrm{T}_{4}$ levels and inhibited ID-II activity in combined Se and I deficiency. This would be consistent with $\mathrm{T}_{3}$ regulation of the levels of uncoupling protein mRNA in BAT (Bianco et al. 1988). Since the levels of uncoupling protein in BAT play an important role in its thermogenic capacity, combined Se and I deficiency is likely to impair the ability of neonatal animals to generate heat and could have implications for their survival during cold stress. Ruminant BAT contains ID-I rather than ID-II, the activity being present only during the first 3 weeks of life. If the generally greater sensitivity of ID-I, compared with ID-II, to Se deficiency applies to ruminant BAT, there may be an important Se-I interaction in the response of neonatal ruminants to cold stress. However, this hypothesis requires further investigation to assess its relevance to survival of farm animals in cold conditions.

\section{Selenium and iodine deficiency: species differences in responses?}

In contrast to rats and human subjects, many other animals such as cattle, sheep and goats do not express significant thyroidal ID-I activity under normal conditions and thus probably have to rely entirely on de novo synthesis of $\mathrm{T}_{3}$ in Se deficiency (Beech et al. 1993). However, I deficiency increased thyroidal ID-I activity 10-12-fold in cows and their calves, although the final activity was still lower than normal levels in rats and human subjects. Thyroidal $c$ GSHPx activities were also increased, probably in response to the higher levels of $\mathrm{H}_{2} \mathrm{O}_{2}$ 
produced to stimulate thyroid hormone synthesis (Zagrodzki et al. 1998). Thus I-deficient cows and their calves can induce similar compensatory mechanisms as rats in order to maintain thyroid hormone synthesis and metabolism, allowing them to appear 'clinically normal'. However, these animals had adequate intake of Se and it is uncertain whether Se deficiency would impair this compensatory response (McCoy et al. 1997; Zagrodzki et al. 1998).

I supplementation of Se-deficient, pregnant ewes decreased plasma $\mathrm{T}_{3}$ concentrations in their lambs (Donald et al. 1993). Goat kids from Se- and I-deficient mothers also had decreased plasma $\mathrm{T}_{3}$ concentrations on I supplementation (Wichtel et al. 1996). Se and I deficiencies have been associated with perinatal calf mortality; however, supplementing cows before and during gestation restored any thyroid hormone imbalance, but did not reduce calf mortality (Mee \& Rogers, 1996). In addition, when lambs were partially immersed in water of progressively declining temperatures, their thermoregulatory ability was unaffected by Se status and there were no Se and I interactions (Donald et al. 1994). However, the deficiencies reported in these experiments were subclinical and the studies rarely compared the thyroid status of the animals before supplementation, which makes any possible Se and I interactions difficult to interpret. Further work is required to determine the effects of concurrent Se and I deficiencies on selenoprotein function and thyroid hormone status in farm animals.

\section{Selenium and iodine deficiency in human subjects}

Studies with experimental Se and I deficiencies in animals have provided a basis for the understanding of the deficiencies in human populations. In man attention has focused on how Se deficiency may alter the effects of I deficiency and how the deficiencies relate to the different forms of endemic cretinism.

\section{Endemic cretinism}

Endemic cretinism is found in areas of severe endemic goitre, the incidence being as high as $15 \%$ of the population. Affected individuals have subnormal intellect and physical development. Two forms of the disorder occur and in both the abnormalities are irreversible once present (Delange \& Ermans, 1996): myxoedematous cretinism and neurological cretinism. In myxoedematous cretinism there is severe hypothyroidism and stunted growth. The prevalence of goitre in myxoedematous cretinism is much lower than that in non-cretins and in many subjects no thyroid tissue may be palpable, with only small amounts of functional tissue being found on thyroid scanning. Typically plasma $\mathrm{T}_{4}$ and $\mathrm{T}_{3}$ are very low whilst TSH is extremely high. The fact that bone age in many cretins corresponds to a fetus of 7-8 months suggests that thyroid destruction must have occurred in utero or soon after birth. In neurological cretinism mental deficiency may be accompanied by neurological problems including hearing and speech defects. Growth and thyroid function are usually normal. The neurological form is more common than myxoedematous cretinism.

The pathogenesis of cretinism is unclear but I deficiency certainly plays an important role since the diseases may be prevented by I supplementation. However, additional factors, which may vary with geographical location, may influence the prevalence and type of disease. These additional factors may include goitrogens, and deficiency in certain trace elements (see later). 
The effect of combined iodine and selenium deficiency in human subjects

The first clue that Se intake may modulate the effects of I deficiency in human subjects came with the study of the cretinism endemia in the Island of Idjwi in Zaire (Goyens et al. 1987; Corvilain et al. 1993). As in other parts of Zaire, there was a high incidence of myxoedematous rather than of neurological cretinism. The distribution of endemia cretinism was related to clear geological areas with severe myxoedematous cretinism occurring in the north and a mild endemic occurring in the south of the island. It was proposed that the thyroid atrophy found in myxoedematous cretinism resulted from thyroid destruction brought about by loss of protection from toxic levels of $\mathrm{H}_{2} \mathrm{O}_{2}$. Trace elements are important for the synthesis of a number of enzymes that are involved in detoxification of oxygen-derived free radicals. Se is needed for activation of glutathione peroxidases and other selenoenzymes described earlier and $\mathrm{Cu}$ and $\mathrm{Zn}$ are required for synthesis of superoxide dismutase. Dietary $\mathrm{Cu}$ and $\mathrm{Zn}$ supplies appeared normal on Idjwi island with no differences between the north and south (Cornil et al. 1974), but Se deficiency was prevalent. Moreover, Se deficiency, I deficiency and thiocyanate overload were all more marked in the north than the south (Goyens et al. 1987; Corvilain et al. 1993).

These observations gave rise to the following hypothesis. When I supply is limited, thyroid hormone synthesis is impaired and TSH concentrations rise, which in turn leads to increased generation of $\mathrm{H}_{2} \mathrm{O}_{2}$. Furthermore, TSH concentration greatly increases after birth and this in turn leads to a marked increase in the generation of $\mathrm{H}_{2} \mathrm{O}_{2}$ in the neonatal thyroid. Under normal circumstances, the $\mathrm{H}_{2} \mathrm{O}_{2}$ so formed is utilized by thyroid peroxidase to incorporate iodide into thyroglobulin. Any excess $\mathrm{H}_{2} \mathrm{O}_{2}$ that diffuses into the thyrocyte from the follicular lumen is detoxified by enzymes such as $c$ GSHPx and catalase (EC 1.11.1.6). Utilization of $\mathrm{H}_{2} \mathrm{O}_{2}$ would also be diminished in I deficiency, due to lack of iodide as substrate for thyroid peroxidase, and this could also increase $\mathrm{H}_{2} \mathrm{O}_{2}$ concentration in the gland. It was suggested that if the thyrocyte lost its ability to protect itself from the peroxidative stress generated in I deficiency, then thyroid atrophy would result. Since the expression of $c$ GSHPx in the thyrocyte in the presence of TSH is largely regulated by Se supply, Se deficiency concurrent with I deficiency could explain the high prevalence of myxoedematous cretinism in the north of the island, the Se deficiency leading to loss of synthesis of glutathione peroxidase. The proposed role of Se deficiency in the pathogenesis of myxoedematous cretinism is shown in Fig. 2.

Further support for this hypothesis came from studies in the endemic goitre belt of northern Zaire (Vanderpas et al. 1990, 1992, 1993; Contempre et al. 1991, 1992; Thilly et al. 1992). In this area the prevalence rate of cretinism was $2-6 \%$, with $80 \%$ of these of the myxoedematous form. Serum Se levels in children living in the goitre belt (Kawara villages) were much lower than those in adults from villages on the border of the endemia area (Vanderpas et al. 1990) and indeed in some children were as low as values found in areas of China regarded as severely Sedeficient. Furthermore, erythrocyte $c$ GSHPx activity was 5-fold lower in the Kawara children than in adults living in a non-I-deficient area of Zaire. In the Kawara villages serum Se and erythrocyte $c$ GSHPx levels were similar in cretins and normal children (Vanderpas et al. 1990).

\section{Selenium and endemic cretinism}

Some recent studies have failed to provide convincing support for the hypothesis that Se deficiency is the only compounding factor responsible for the endemic cretinism seen in some I-deficient areas. Myxoedematous cretinism does not occur in certain provinces of Africa with a similar degree of Se deficiency but a greater degree of I deficiency than Zaire (Ngo et al. 1997). Similarly there is severe I and Se deficiency in areas of Tibet but the incidence of myx- 


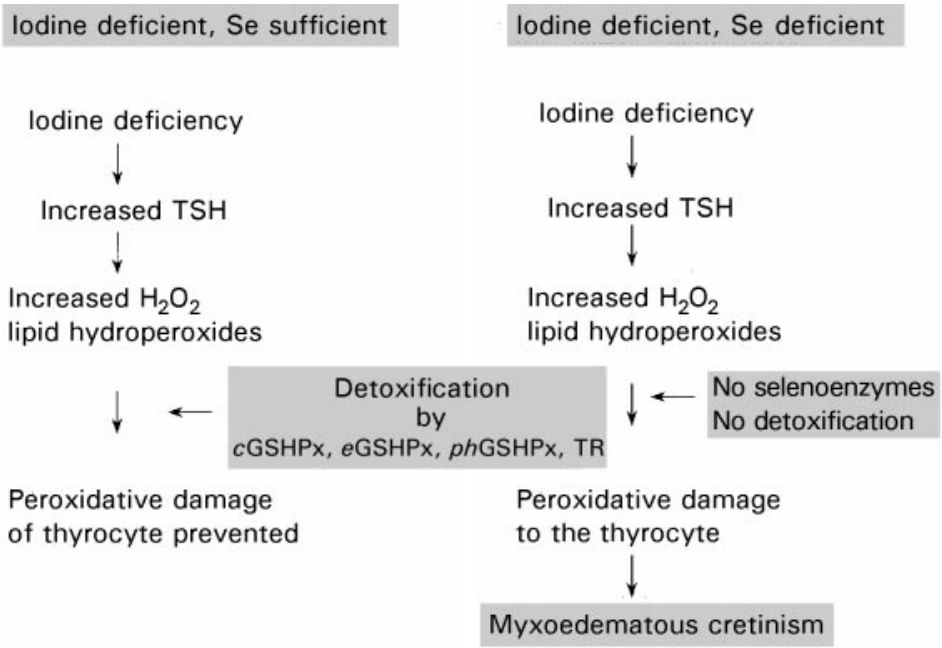

Fig. 2. A mechanism for the development of myxoedematous cretinism in combined selenium and iodine deficiency. In the presence of adequate selenium, selenoproteins protect the thyroid from excess hydrogen peroxide production occurring in response to iodine deficiency. When selenium is limiting, impaired hydrogen peroxide metabolism allows damage to the thyroid and involution associated with myxoedematous cretinism. cGSHPx, cytosolic glutathione peroxidase; eGSHPx, extracellular glutathione peroxidase; phGSHPx, phospholipid hydroperoxide glutathione peroxidase; TR, thioredoxin reductase; TSH, thyrotropin.

oedematous cretinism is very low with neurological cretinism predominating (Morenoreyes et al. 1998; Vanderpas, 1998). Combined I and Se deficiency therefore does not appear to be sufficient to explain the elevated frequency of myxoedematous cretinism in central Africa. The possible role of other additional factors such as thiocyanates (Thilly et al. 1992) must again be considered (Morenoreyes et al. 1998).

\section{Selenium supplementation of iodine-deficient subjects}

When normal school-children and cretins in the Kawara villages were given a supplement of $50 \mu \mathrm{g} \mathrm{Se} / \mathrm{d}$ (as selenomethionine) or placebo for 2 months (Contempre et al. 1991, 1992; Vanderpas et al. 1992), serum Se and erythrocyte $c$ GSHPx were normalized. In addition, plasma $\mathrm{T}_{4}$ levels decreased. In the cretins there was a marked fall in total $\mathrm{T}_{4}$ levels from a mean of 12.8 (SD 5.1) nmol/1 to 2.8 (SD 2.5) nmol/1 (Contempre et al. 1991, 1992; Vanderpas et al. 1993). The lower limit of normal values in many European countries is approximately $60 \mathrm{nmol} / 1$. Following Se supplementation, mean TSH concentrations increased significantly from $262 \mathrm{mU} / 1$ to $363 \mathrm{mU} / \mathrm{l}$. There was no significant change in total $\mathrm{T}_{3}$ or surprisingly no change in plasma free $T_{4}$, but this may have been due to methodological problems in the free $T_{4}$ assays available at the time of the study. Indeed total $\mathrm{T}_{4}$ concentrations fell without any changes in thyroxine-binding globulin concentrations, suggesting that free $\mathrm{T}_{4}$ concentrations should have also fallen in response to Se supplementation (Contempre et al. 1991, 1992; Vanderpas et al. 1992). In the normal school-children, Se supplementation resulted in a fall in plasma $\mathrm{T}_{4}$ without a concomitant rise in $\mathrm{TSH}$. 
A similar observation has been made in children with phenylketonuria. Their I intakes were adequate but $\mathrm{Se}$ intake was low due to the low-protein diet they eat. Administering Se produced a $16 \%$ fall in plasma $T_{4}$ and reverse $T_{3}$ (Calomme et al. 1995). The fall in $T_{4}$ in cretins was attributed to an increase in the expression of hepatic ID-I which in turn would increase the metabolism of plasma $T_{4}$ to $T_{3}$ (Vanderpas et al. 1993). In normal children, with adequate amounts of functional thyroid tissue, the gland would be able to meet the increased requirement for $\mathrm{T}_{4}$ synthesis following the induction of ID-I expression caused by Se supplementation. In contrast to normal children the cretins have small fibrosed thyroid glands that exhibit impaired I uptake (Contempre et al. 1996). This small amount of functional thyroid tissue was thought to be insufficient to meet the increased requirement for thyroid hormone synthesis (Contempre et al. 1991, 1992) after Se supplementation enhanced ID-I expression (Vanderpas et al. 1992). However, thyroid function in most cretins improved when I supplements were given, suggesting that I availability was also a limiting step of thyroid hormone production (Contempre et al. 1991). It is likely therefore that in cretins the increased requirement for thyroid hormone synthesis after Se supplements often leads to rapid depletion of I reserves.

\section{Selenium deficiency protects against iodine deficiency?}

These observations have also led to the intriguing hypothesis that Se deficiency may protect from some of the effects of I deficiency particularly fetal brain development (Vanderpas et al. 1990, 1993; Contempre et al. 1992). The $T_{3}$ occupying the nuclear receptors in different organs arises from different sources. In the kidney approximately $80 \%$ of $\mathrm{T}_{3}$ is derived from plasma $\mathrm{T}_{3}$ and not from deiodination of $\mathrm{T}_{4}$ taken up from the plasma. In contrast the brain appears to utilize mainly $\mathrm{T}_{3}$ derived from uptake of plasma $\mathrm{T}_{4}$, which is then deiodinated by ID-II within the cell (Beckett \& Arthur, 1994). Maternal $\mathrm{T}_{4}$ is also thought to provide an important source of $\mathrm{T}_{4}$ for fetal brain during pregnancy (Deescobar et al. 1993). Thus because Se deficiency often leads to higher plasma $\mathrm{T}_{4}$ concentrations, it may actually help to protect the fetal brain during development. This implies that it is unethical to supplement a population deficient in both $\mathrm{Se}$ and I with Se alone since this might exacerbate the risk of abnormal brain development. Thus although Se deficiency in an I-deficient population may favour thyroid destruction and myxoedematous cretinism, it may also protect against the neurological form of the disease (Vanderpas et al. 1990, 1993; Contempre et al. 1992).

These hypotheses are interesting but are not absolutely proven. Although $\mathrm{T}_{4}$ supply to the brain is important, the crucial determinant of brain development is the amount of $\mathrm{T}_{3}$ located on the nuclear receptors and thus ID-II activity in the brain must also be considered. In rats and man I deficiency leads to an induction of ID-II in the brain and as discussed earlier, this is enhanced further in the rat if it is also Se-deficient (Beckett et al. 1993; Karmarkar et al. 1993). If the effects of combined Se and I deficiency on ID-II in the brain in man are similar to the rat (i.e. ID-II is induced to levels higher than in I deficiency alone) Se deficiency might indeed protect against neurological cretinism in I-deficient areas. The possible role of Se deficiency in preventing neurological cretinism is shown in Fig. 3.

\section{Selenium as an antioxidant in the thyroid}

In the rat thyroid and in cultured human thyrocytes, Se deficiency has only a modest effect on the expression of $c$ GSHPx (Beech et al. 1995). This might suggest it is not the loss of this 


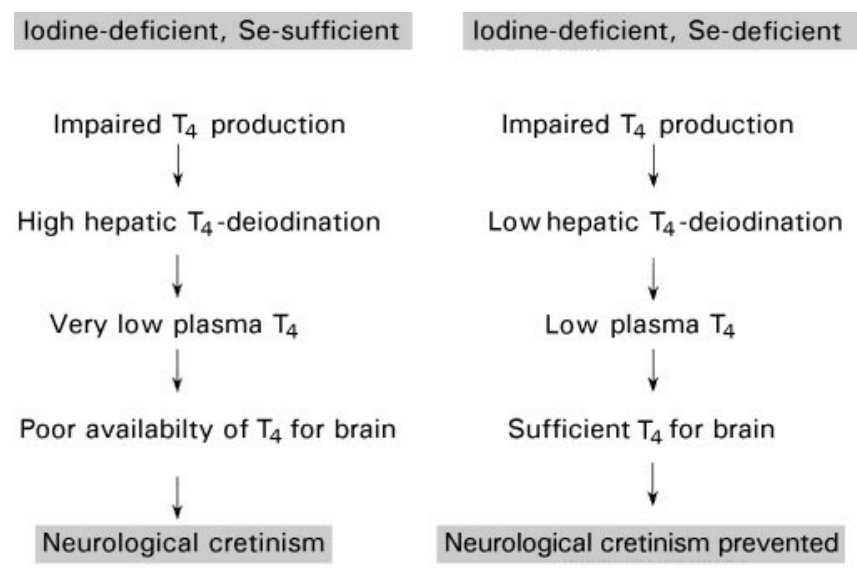

Fig. 3. A mechanism for protection against neurological cretinism in combined selenium and iodine deficiency. In selenium-adequate, iodine-deficient conditions circulating thyroxine $\left(T_{4}\right)$ is metabolized by peripheral deiodination and the hormone is not available to protect the brain from neurological cretinism. In combined selenium and iodine deficiency peripheral $\mathrm{T}_{4}$ metabolism is impaired and the hormone is available to prevent brain damage.

enzyme that gives rise to increased susceptibility to oxidative damage, but rather some other selenoprotein may be more important in this regard. Alternatively, in circumstances such as I deficiency, Se deficiency may prevent compensatory increases in selenoperoxidases that normally cope with oxidative stress.

TR may be involved in protecting the thyrocyte from oxidative damage. It has a broad substrate specificity and, with NADPH as a cofactor, reacts with a wide range of substrates including thioredoxin, peroxides, selenodiglutathione, selenite and glutathione peroxidase (Holmgren \& Bjornstedt, 1995). The thioredoxin-TR redox system can act as cofactor for reactions catalysed by ID-I (Sharifi \& St Germain, 1992). TR can also detoxify both lipid hydroperoxides and $\mathrm{H}_{2} \mathrm{O}_{2}$ and may serve as an important alternative detoxification pathway to the Se-dependent glutathione peroxidases (Bjornstedt et al. 1995). It is significant that $c$ GSHPx appears to be ineffective at degrading high concentrations of $\mathrm{H}_{2} \mathrm{O}_{2}$ in the rat thyrocyte cell line FRTL5 (Bjorkman \& Ekholm, 1995). This detoxification role for TR may be of special importance in the thyrocyte since high concentrations of peroxides are generated during thyroid hormone synthesis. Indeed the expression of TR can be greatly increased in human thyrocytes through activation of the $\mathrm{Ca}$-phosphoinositol signalling pathway that also stimulates $\mathrm{H}_{2} \mathrm{O}_{2}$ production (Beckett et al. 1998; Howie et al. 1998). Thus, it could be argued that the development of myxoedematous cretinism in areas of Se and I deficiency may result from loss of TR expression in the thyroid rather than loss of $c$ GSHPx activity (Beckett et al. 1998; Howie et al. 1998).

$e$ GSHPx is another selenoenzyme expressed by the thyroid gland and secreted into the extracellular space under the regulation of the $\mathrm{Ca}$-phosphoinositol signalling pathway (Howie et al. 1995). It may also have a role in protecting the thyrocytes from damage. The decreased expression of $e$ GSHPx when Se supply is low may thus contribute to the thyroid atrophy seen in combined I and Se deficiency.

\section{Conclusions}

Because of the multiplicity of roles of selenoproteins in thyroid hormone metabolism and elsewhere, Se can have both beneficial and adverse effects on man and animals with I defi- 
ciency. In human subjects, a concurrent Se deficiency has a sparing effect on plasma $T_{4}$ concentrations as compared with I-deficient individuals, providing a role for Se deficiency in the protection against neurological cretinism (Contempre et al. 1991). This has not been demonstrated in animals and in some cases, a concurrent Se deficiency can exacerbate the effects of I deficiency on brain biochemistry (Mitchell et al. 1998). Whether this is due to differences between species or in the duration and severity of the deficiencies requires further investigation. Concurrent Se deficiency decreases Se supply to thyroidal ID-I (and ID-II) and glutathione peroxidases, causing a decrease in plasma and tissue $T_{3}$ concentrations, but does not induce the thyroid involution characteristic of myxoedematous cretinism (Beckett $e t$ al. 1993; Mitchell et al. 1996; Zagrodzki et al. 1998). However, the hypothyroid stress on the thyroid gland is significantly increased in concurrent Se and I deficiency as compared with I deficiency alone. Furthermore, the increased sensitivity of the Se-deficient thyroid gland to free radical attack in I deficiency has been confirmed in rats in which thyroid tissue was damaged by goitrogens (Contempre et al. 1995, 1996; Mitchell et al. 1996, 1998). Goitrogens may also play a significant role in the aetiology of myxoedematous cretinism, although there is no doubt that a concurrent Se deficiency will aggravate the hypothyroid stress in man and animals suffering from the damaging effects of I deficiency. Animal models of Se and I deficiency show many similarities to I deficiency diseases in human subjects, but do not mirror them exactly. Thus if Se deficiency is involved in the outcome of I deficiency in man, it is likely that other interacting factors such as goitrogens are also involved. Additionally, the ability of Se deficiency to modify the toxicity of viruses could underlie the outcome of I deficiency, particularly if the viruses attack the thyroid or the brain (Levander \& Beck, 1997). Nevertheless, the protection of the thyroid gland from $\mathrm{H}_{2} \mathrm{O}_{2}$ and the regulation of tissue $\mathrm{T}_{3}$ levels are the functions of Se that are most likely to underlie the interactions of Se and I. Further research may, however, reveal that this is an oversimplification of a very complex interaction.

\section{Acknowledgement}

We are grateful to the Scottish Office Agriculture Environment and Fisheries Department for financial support (J. R. A., J. H. M.).

\section{References}

Arthur JR \& Beckett GJ (1994) New metabolic roles for selenium. Proceedings of the Nutrition Society 53, 615-624. Arthur JR, Bermano G, Mitchell JH \& Hesketh JE (1996) Regulation of selenoprotein gene expression and thyroid hormone metabolism. Biochemical Society Transactions 24, 384-388.

Arthur JR, Nicol F \& Beckett GJ (1990a) Hepatic iodothyronine deiodinase: The role of selenium. Biochemical Journal 272, 537-540.

Arthur JR, Nicol F, Beckett GJ \& Trayhurn P (1991) Impairment of iodothyronine 5'-deiodinase activity in brown adipose tissue and its acute stimulation by cold in selenium deficiency. Canadian Journal of Physiology and Pharmacology 69, 782-785.

Arthur JR, Nicol F, Boyne R, Allen KGD, Hayes JD \& Beckett GJ (1987) Old and new roles for selenium. In Trace Substances in Environmental Health XXI, pp. 487-498 [DD Hemphill, editor]. Colombia, MO: University of Missouri.

Arthur JR, Nicol F, Hutchinson AR \& Beckett GJ (1990b) The effects of selenium depletion and repletion on the metabolism of thyroid hormones in the rat. Journal of Inorganic Biochemistry 39, 101-108.

Arthur JR, Nicol F, Rae PWH \& Beckett GJ (1990c) Effects of selenium deficiency on the thyroid gland and on plasma and pituitary thyrotrophin and growth hormone concentrations in the rat. Clinical Chemistry and Enzymology Communications 3, 209-214. 
Beck MA, Shi Q, Morris VC \& Levander OA (1995) Rapid genomic evolution of a non-virulent Coxsackievirus B3 in selenium-deficient mice results in selection of identical virulent isolates. Nature-Medicine 1, 433-436.

Beckett GJ \& Arthur JR (1994) The iodothyronine deiodinases and 5'-deiodination. Baillieres Clinical Endocrinology and Metabolism 8, 285-304.

Beckett GJ, Beddows SE, Morrice PC, Nicol F \& Arthur JR (1987) Inhibition of hepatic deiodination of thyroxine caused by selenium deficiency in rats. Biochemical Journal 248, 443-447.

Beckett GJ, Howie AF, Nicol F, Walker SW, Beech SG \& Arthur JR (1998) Human thioredoxin reductase expression is regulated through the Ca phosphoinositol signalling cascade. In Metal Ions in Biology and Medicine, vol. 5, pp. 519523 [P Collery, P Bratter, V Negretti de Bratter, L Khassanova and JC Etienne, editors]. Paris: John Libbey Eurotext.

Beckett GJ, MacDougall DA, Nicol F \& Arthur JR (1989) Inhibition of type I and type II iodothyronine deiodinase activity in rat liver, kidney and brain produced by selenium deficiency. Biochemical Journal 259, 887-892.

Beckett GJ, Nicol F, Rae PWH, Beech S, Guo YM \& Arthur JR (1993) Effects of combined iodine and selenium deficiency on thyroid hormone metabolism in rats. American Journal of Clinical Nutrition 57, S240-S243.

Beech SG, Walker SW, Beckett GJ, Arthur JR, Nicol F \& Lee D (1995) Effect of selenium depletion on thyroidal typeI iodothyronine deiodinase activity in isolated human thyrocytes and rat thyroid and liver. Analyst 120, 827-831.

Beech SG, Walker SW, Dorrance AM, Arthur JR, Nicol F, Lee D \& Beckett GJ (1993) The role of thyroidal type-I iodothyronine deiodinase in tri-iodothyronine production by human and sheep thyrocytes in primary culture. Journal of Endocrinology 136, 361 - 370.

Behne D, Hilmert H, Scheid S, Gessner H \& Elger W (1988) Evidence for specific selenium target tissues and new biologically important selenoproteins. Biochimica et Biophysica Acta 966, 12-21.

Behne D, Kyriakopoulos A, Meinhold H \& Kohrle J (1990) Identification of type-I iodothyronine 5'-deiodinase as a selenoenzyme. Biochemical and Biophysical Research Communications 173, 1143-1149.

Behne D, Kyriakopoulos A, Weissnowak C, Kalckloesch M, Westphal C \& Gessner H (1996) Newly found seleniumcontaining proteins in the tissues of the rat. Biological Trace Element Research 55, 99-110.

Bermano G, Nicol F, Dyer JA, Sunde RA, Beckett GJ, Arthur JR \& Hesketh JE (1995) Tissue-specific regulation of selenoenzyme gene expression during selenium deficiency in rats. Biochemical Journal 311, 425-430.

Berry MJ, Banu L, Chen Y, Mandel SJ, Kieffer JD, Harney JW \& Larsen PR (1991a) Recognition of UGA as a selenocysteine codon in type-I deiodinase requires sequences in the $3^{\prime}$ untranslated region. Nature 353, $273-276$.

Berry MJ, Banu L \& Larsen PR (1991b) Type-I iodothyronine deiodinase is a selenocysteine-containing enzyme. Nature 349, 438-440.

Berry MJ, Kieffer JD, Harney JW \& Larsen PR (1991c) Selenocysteine confers the biochemical properties characteristic of the type-I iodothyronine deiodinase. Journal of Biological Chemistry 266, 14155-14158.

Bianco AS, Sheng X \& Silva JE (1988) Triiodothyronine amplifies norepinephrine stimulation of uncoupling protein gene transcription by a mechanism requiring protein synthesis. Journal of Biological Chemistry 263, $18168-18172$.

Bjorkman U \& Ekholm R (1992) Hydrogen peroxide generation and its regulation in FRTL5 and porcine thyroid cells. Endocrinology 130, 393-399.

Bjorkman U \& Ekholm R (1995) Hydrogen peroxide degradation and glutathione peroxidase activity in cultures of thyroid cells. Molecular and Cellular Endocrinology 111, 99-107.

Bjornstedt M, Hamberg M, Kumar S, Xue J \& Holmgren A (1995) Human thioredoxin reductase directly reduces lipid hydroperoxides by NADPH and selenocystine strongly stimulates the reaction via catalytically generated selenols. Journal of Biological Chemistry 270, 11761-11764.

Burk RF \& Hill KE (1992) Some properties of selenoprotein-P. Biological Trace Element Research 33, $151-153$.

Burk RF, Hill KE, Awad JA, Morrow JD, Kato T, Cockell KA \& Lyons PR (1995) Pathogenesis of diquat-induced liver necrosis in selenium-deficient rats: Assessment of the roles of lipid peroxidation and selenoprotein P. Hepatology 21, $561-569$.

Calomme MR, Vanderpas JB, Francois B, Vancailliebertrand M, Herchuelz A, Vanovervelt N, Vanhoorebeke C \& Berghe DAV (1995) Thyroid function parameters during a selenium repletion depletion study in phenylketonuric subjects. Experimentia 51, 1208-1215.

Campos-Barros A, Meinhold H, Walzog B \& Behne D (1997) Effects of selenium and iodine deficiency on thyroid hormone concentrations in the central nervous system of the rat. European Journal of Endocrinology 136, $316-323$.

Chanoine JP, Braverman LE, Farwell AP, Safran M, Alex S, Dubord S \& Leonard JL (1993) The thyroid gland is a major source of circulating-T(3) in the rat. Journal of Clinical Investigation 91, 2709-2713.

Chanoine JP, Safran M, Farwell AP, Tranter P, Ekenbarger DM, Dubord S, Alex S, Arthur JR, Beckett GJ, Braverman LE \& Leonard JL (1992) Selenium deficiency and type-II 5'-deiodinase regulation in the euthyroid and hypothyroid rat - evidence of a direct effect of thyroxine. Endocrinology 131, 479-484.

Contempre B, Denef JF, Dumont JE \& Many MC (1993) Selenium deficiency aggravates the necrotizing effects of a high iodide dose in iodine deficient rats. Endocrinology 132, 1866-1868.

Contempre B, Duale NL, Dumont JE, Ngo B, Diplock AT \& Vanderpas JB (1992) Effect of selenium supplementation on thyroid hormone metabolism in an iodine and selenium deficient population. Clinical Endocrinology 36, $579-583$.

Contempre B, Dumont JE, Denef JF \& Many MC (1995) Effects of selenium deficiency on thyroid necrosis, fibrosis and proliferation: A possible role in myxoedematous cretinism. European Journal of Endocrinology 133, 99-109. 
Contempre B, Dumont JE, Ngo B, Thilly CH, Diplock AT \& Vanderpas JB (1991) Effect of selenium supplementation in hypothyroid subjects of an iodine and selenium deficient area - the possible danger of indiscriminate supplementation of I-deficient subjects with selenium. Journal of Clinical Endocrinology and Metabolism 73, $213-215$.

Contempre B, LeMoine O, Dumont JE, Denef JF \& Many MC (1996) Selenium deficiency and thyroid fibrosis. A key role for macrophages and transforming growth factor beta (TGF-beta). Molecular and Cellular Endocrinology 124, $7-15$.

Cornil J, Ledent C, Vanderstappen R, Herman P, Van der Velden M \& DeLange F (1974) Comparative studies of the chemical composition of vegetation, soils in goitrous and non-goitrous regions of Idjwi Islands (Lake Kivu, Republic of Zaire). Bulletin seleniumances Academie Sciences Outremer (Brussels) 3, 386-402.

Corvilain B, Contempre B, Longombe AO, Goyens P, Gervydecoster C, Lamy F, Vanderpas JB \& Dumont JE (1993) Selenium and the thyroid - how the relationship was established. American Journal of Clinical Nutrition 57, S244-S248.

Corvilain B, Laurent E, Lecomte M, Vasande J \& Dumont JE (1994) The role of cyclic adenosine- $3^{\prime}, 5^{\prime}$ monophosphate and phosphatidylinositol $\mathrm{Ca}^{2+}$ cascades in mediating the effects of thyrotropin and iodide on hormone synthesis and secretion in human thyroid slices. Journal of Clinical Endocrinology and Metabolism 79, 152-159.

Croteau W, Davey JC, Galton VA \& St Germain DL (1996) Cloning of the mammalian type II iodothyronine deiodinase - A selenoprotein differentially expressed and regulated in human and rat brain and other tissues. Journal of Clinical Investigation 98, 405-417.

Croteau W, Whittemore SL, Schneider MJ \& St Germain DL (1995) Cloning and expression of a cDNA for a mammalian type III iodothyronine deiodinase. Journal of Biological Chemistry 270, 16569-16575.

Dai G, Levy O \& Carrasco N (1996) Cloning and characterization of the thyroid iodide transporter. Nature 379, 458-460.

Deescobar GM, Obregon MJ, Calvo R \& Delrey FE (1993) Effects of iodine deficiency on thyroid hormone metabolism and the brain in fetal rats - the role of the maternal transfer of thyroxin. American Journal of Clinical Nutrition 57, S280-S285.

Delange FM \& Ermans AM (1996) Iodine deficiency. In Werner and Ingbar's The Thyroid, 7th ed., pp. 296-316 and pp. 736-767 [LE Braverman and RD Utiger, editors]. Philadelphia, PA: Lippincott-Raven.

Donald GE, Langlands JP, Bowles JE \& Smith AJ (1993) Subclinical selenium insufficiency. 4. Effects of selenium, I, and thiocyanate supplementation of grazing ewes on their selenium and iodine status, and on the status and growth of their lambs. Australian Journal of Experimental Agriculture 33, 411-416.

Donald GE, Langlands JP, Bowles JE \& Smith AJ (1994) Subclinical selenium insufficiency. 6. Thermoregulatory ability of perinatal lambs born to ewes supplemented with selenium and I. Australian Journal of Experimental Agriculture 34, 19-24.

Dumont JE (1971) The action of thyrotropin on thyroid metabolism. Vitamins and Hormones 29, $287-412$.

Evenson JK \& Sunde RA (1988) Selenium incorporation into selenoproteins in the Se-adequate and Se- deficient rat. Proceedings of the Society for Experimental Biology and Medicine 187, 169-180.

Ge K \& Yang GQ (1993) The epidemiology of selenium deficiency in the etiological study of endemic diseases in China. American Journal of Clinical Nutrition 57, S259-S263.

Geloen A, Arthur JR, Beckett GJ \& Trayhurn P (1990) Effect of selenium and iodine deficiency on the level of uncoupling protein in brown adipose tissue of rats. Biochemical Society Transactions 18, 1269-1270.

Gladyshev VN, Jeang KT \& Stadtman TC (1996) Selenocysteine, identified as the penultimate C-terminal residue in human T-cell thioredoxin reductase, corresponds to TGA in the human placental gene. Proceedings of the National Academy of Sciences USA 93, 6146-6151.

Goyens P, Golstein J, Nsombola B, Vis H \& Dumont JE (1987) Selenium deficiency as a possible factor in the pathogenesis of myxoedematous cretinism. Acta Endocrinologica (Copenhagen) 114, 497-502.

Gu QP, Xia YM, Ha PC, Butler JA \& Whanger PD (1998) Distribution of selenium between plasma fractions in guinea pigs and humans with various intakes of dietary selenium. Journal of Trace Elements in Medicine and Biology 12, 8-15.

Hill KE, Lloyd RS, Yang JG, Read R \& Burk RF (1991) The cDNA for rat selenoprotein-P contains 10 TGA Codons in the open reading frame. Journal of Biological Chemistry 266, 10050-10053.

Holmgren A \& Bjornstedt M (1995) Thioredoxin and thioredoxin reductase. Methods in Enzymology 252, $199-208$.

Hotz CS, Fitzpatrick DW, Trick KD \& L'Abbe MR (1997) Dietary iodine and selenium interact to affect thyroid hormone metabolism of rats. Journal of Nutrition 127, 1214-1218.

Howie AF, Arthur JR, Nicol F, Walker SW, Beech SG \& Beckett GJ (1998) Identification of a 57-kilodalton selenoprotein in human thyrocytes as thioredoxin reductase and evidence that its expression is regulated through the calcium-phosphoinositol signalling pathway. Journal of Clinical Endocrinology and Metabolism 83, 2052-2058.

Howie AF, Walker SW, Akesson B, Arthur JR \& Beckett GJ (1995) Thyroidal extracellular glutathione peroxidase: A potential regulator of thyroid-hormone synthesis. Biochemical Journal 308, 713-717.

Karmarkar MG, Prabarkaran D \& Godbole MM (1993) 5'-Monodeiodinase activity in developing human cerebral cortex. American Journal of Clinical Nutrition 57, S291-S294.

Kohrle J (1994) Thyroid hormone deiodination in target tissues - A regulatory role for the trace element selenium? Experimental and Clinical Endocrinology 102, 63-89.

KoopdonkKool JM, deVijlder JJM, Veenboer GJM, RisStalpers C, Kok JH, Vulsma T, Boer K \& Visser TJ (1996) Type II and type III deiodinase activity in human placenta as a function of gestational age. Journal of Clinical Endocrinology and Metabolism 81, 2154-2158. 
Kristensson K, Zeller NK, Dubois-Dalcq ME \& Lazzarini RA (1986) Expression of myelin basic protein gene in the developing rat brain as revealed by in situ hybridization. Journal of Histochemistry and Cytochemistry 34, $467-473$.

Larsen PR (1996) Mammalian type 2 deiodinase sequences: Finally, the end of the beginning. Journal of Clinical Investigation 98, 242.

Larsen PR \& Berry MJ (1995) Nutritional and hormonal regulation of thyroid hormone deiodinases. Annual Review of Nutrition 15, 323-352.

Levander OA \& Beck MA (1996) Viral evolution as driven by host nutritional selective factors: Influence of dietary oxidative stress. Food Chemistry 57, 47-49.

Levander OA \& Beck MA (1997) Interacting nutritional and infectious etiologies of Keshan disease - Insights from Coxsackie virus B-induced myocarditis in mice deficient in selenium or vitamin E. Biological Trace Element Research 56, 5-21.

McCoy MA, Smyth JA, Ellis WA, Arthur JR \& Kennedy DG (1997) Experimental reproduction of iodine deficiency in cattle. Veterinary Record 141, 544-547.

McLeod R, Ellis EM, Arthur JR, Neal GE, Judah DJ, Manson MM \& Hayes JD (1997) Protection conferred by selenium deficiency against aflatoxin B-1 in the rat is associated with the hepatic expression of an aldo-keto reductase and a glutathione S-transferase subunit that metabolize the mycotoxin. Cancer Research 57, 4257-4266.

Mee JF \& Rogers PAM (1996) Relevance of I, selenium, copper and cobalt deficiencies on Irish cattle farms. Irish Veterinary Journal 49, 529.

Meinhold H, Campos-Barros A, Walzog B, Kohler R, Muller F \& Behne D (1993) Effects of selenium and iodine deficiency on type-I, type-II and type-III iodothyronine deiodinases and circulating thyroid hormones in the rat. Experimental and Clinical Endocrinology 101, 87-93.

Mitchell JH, Nicol F, Beckett GJ \& Arthur JR (1996) Selnoenzyme expression in thyroid and liver of second generation selenium- and I-deficient rats. Journal of Molecular Endocrinology 16, 259-267.

Mitchell JH, Nicol F, Beckett GJ \& Arthur JR (1997) Selenium and iodine deficiencies: effects on brain and brown adipose tissue selenoenzyme activity and expression. Journal of Endocrinology 155, 255-263.

Mitchell JH, Nicol F, Beckett GJ \& Arthur JR (1998) Selenoprotein expression and brain development in preweanling selenium- and I-deficient rats. Journal of Molecular Endocrinology 20, 203-210.

Morenoreyes R, Suetens C, Mathieu F, Begaux F, Perlmutter N, Boelaert M, Phelmo D, Neve J \& Vanderpas J (1998) Iodine and selenium deficiency in Kashin Beck disease (Tibet). New England Journal of Medicine 339, $1112-1120$.

Ngo B, Dikassa L, Okitolonda W, Kashala TD, Gervy C, Dumont JE, Yanovervelt N, Contempre B, Diplock AT, Peach S \& Vanderpas JB (1997) Selenium status in pregnant women of a rural population (Zaire) in relationship to iodine deficiency. Tropical Medicine and International Health 2, 572-585.

Obregon MJ, Ruiz de Ona C, Calvo R, Escobar del Rey F \& Morreale de Escobar G (1991) Outer ring iodothyronine deiodinases and thyroid hormone economy: responses to iodine deficiency in the rat fetus. Endocrinology 129, $2663-2673$.

Perez-Castillo A, Bernal J, Ferreiro B \& Pans T (1985) The early ontogenesis of thyroid hormone receptor in the rat foetus. Endocrinology 117, 2457-2461.

Richard K, Hume R, Kaptein E, Sanders JP, VanToor H, Deherder WW, DenHollander JC, Krenning EP \& Visser TJ (1998) Ontogeny of iodothyronine deiodinases in human liver. Journal of Clinical Energy and Metabolism 83, 2868-2874.

Safran M, Farwell AP \& Leonard JL (1991) Evidence that type-II 5'-deiodinase is not a selenoprotein. Journal of Biological Chemistry 266, 13477-13480.

Salvatore D, Low SC, Berry M, Maia AL, Harney JW, Croteau W, St Germain DL \& Larsen PR (1995) Type 3 iodothyronine deiodinase: Cloning, in vitro expression, and functional analysis of the placental selenoenzyme. Journal of Clinical Investigation 96, 2421-2430.

Salvatore D, Tu H, Harney JW \& Larsen PR (1996) Type 2 iodothyronine deiodinase is highly expressed in human thyroid. Journal of Clinical Investigation 98, 962-968.

Selrrano-Lozano A, Montiel M, Morell M \& Morata P (1993) 5' Deiodinase activity in brain regions of adult rats Modifications in different situations of experimental hypothyroidism. Brain Research Bulletin 30, 611-616.

Sharifi J \& St Germain DL (1992) The cDNA for the type-I iodothyronine 5'-deiodinase encodes an enzyme manifesting both high $\mathrm{Km}$ and low $\mathrm{Km}$ activity - evidence that rat liver and kidney contain a single enzyme which converts thyroxine to 3,5,3'-triiodothyronine. Journal of Biological Chemistry 267, 12539-12544.

St Germain DL \& Galton VA (1997) The deiodinase family of selenoproteins. Thyroid 7, 655-668.

Sunde RA (1990) Molecular biology of selenoproteins. Annual Review of Nutrition 10, 451-474.

Taurog A (1986) Hormone synthesis and secretion. In Werner and Ingbar's The Thyroid, 7th ed., pp. 47-81 [LE Braverman and RD Utiger, editors]. Philadelphia, PA: Lippincott-Raven.

Thilly CH, Vanderpas JB, Bebe N, Ntambue K, Contempre B, Swennen B, Morenoreyes R, Bourdoux P \& Delange F (1992) Iodine deficiency, other trace elements, and goitrogenic factors in the etiopathogeny of iodine deficiency disorders (IDD). Biological Trace Element Research 32, 229-243.

Vanderpas JB (1998) Human selenium deficiency and thyroid clinical status. In Metal Ions in Biology and Medicine, vol. 5, pp. 549-554 [P Collery, P Bratter, V Negretti de Bratter, L Khassanova and JC Etienne, editors]. Paris: John Libbey Eurotext.

Vanderpas JB, Contempre B, Duale NL, Deckx H, Bebe N, Longombe AO, Thilly CH, Diplock AT \& Dumont JE (1993) Selenium deficiency mitigates hypothyroxinemia in I-deficient subjects. American Journal of Clinical Nutrition 57, S271-S275. 
Vanderpas JB, Contempre B, Duale NL, Goossens W, Bebe N, Thorpe R, Ntambue K, Dumont JE, Thilly CH \& Diplock AT (1990) Iodine and selenium deficiency associated with cretinism in northern Zaire. American Journal of Clinical Nutrition 52, 1087-1093.

Vanderpas JB, Dumont JE, Contempre B \& Diplock AT (1992) Iodine and selenium deficiency in northern Zaire. American Journal of Clinical Nutrition 56, 957-958.

Wichtel JJ, Thompson KG, Craigie AL \& Williamson NB (1996) Effects of selenium and iodine supplementation on the growth rate, mohair production, and thyroid status of Angora goat kids. New Zealand Journal of Agricultural Research 39, 111-115.

Wu HY, Xia YM, Ha PC \& Chen XS (1997) Changes in myocardial thyroid hormone metabolism and alphaglycerophosphate dehydrogenase activity in rats deficient in iodine and selenium. British Journal of Nutrition $\mathbf{7 8}$, $671-676$.

Wu L, Mcgarry L, Lanfear J \& Harrison PR (1995) Altered selenium-binding protein levels associated with selenium resistance. Carcinogenesis 16, 2819-2824.

Zagrodzki P, Nicol F, McCoy MA, Smyth JA, Kennedy DG, Beckett GJ \& Arthur JR (1998) Iodine deficiency in cattle: compensatory changes in thyroidal selenoenzymes. Research in Veterinary Science 64, 209-211. 